\title{
Polymeric Materials for Dielectric Reference Specimens
}

\author{
Arnold H. Scott* and Joseph R. Kinard, Jr. \\ Institute for Basic Standards, National Bureau of Standards, Washington, D.C. 20234
}

(December 1, 1966)

\begin{abstract}
The results from a study of the effects of aging and humidity change on certain polymer specimens indicate it is possible to establish stable dielectric reference specimens. Specimens of polyethylene, polystyrene, polycarbonate, poly(tetrafluoroethylene) (PTFE), fluorinated ethylene-propylene polymer (FEP), and poly(1,4-cyclohexylenedimethylene terephthalate) were used in the investigation. Slow changes in the dielectric properties. were observed on some specimens over a period as long as three years. Very long timed humidity runs indicate PTFE, and FEP to only a slightly less degree, are best suited for dielectric reference specimen preparation.
\end{abstract}

Key Words: Dielectric constant, dissipation factor, frequency, fluorinated ethylene-propylene, humidity, polycarbonate, polyethylene, poly(1,4-cyclohexylenedimethylene terephthalate), polystyrene, poly(tetrafluoroethylene), time, reference specimens.

\section{Introduction}

A long term study of certain polymer specimens under consideration as dielectric reference specimens has been conducted. Such reference specimens may be used to compare the measurement accuracy of various other laboratories, so these specimens must have accurately determined and stable dielectric properties. Specimens from several polymers were found to exhibit sufficient stability to permit their use. The materials investigated were polyethylene (PE), polystyrene (PS), polycarbonate (PC), poly(tetrafluoroethylene) (PTFE), fluorinated ethylene-propylene polymer (FEP), and poly(1,4-cyclohexylenedimethylene terephthalate) $(\mathrm{T}-16)$. All data were taken on flat disk specimens, and the conditions under which the measurements were made were carefully controlled. The humidity of the surrounding atmosphere as well as the specimen temperature was controlled because the properties of most specimens were functions of humidity.

\section{Measuring Equipment}

A low-voltage conjugate Schering bridge similar to one described in a paper by Scott and Harris [1] ${ }^{1}$ was used to measure dielectric constant and dissipation factor from $10^{2} \mathrm{~Hz}$ to $10^{5} \mathrm{~Hz}$. The cell used with the Schering bridge was of the guard-ring micrometerelectrode type $[2,3,4]$ and was mounted in a chamber

*Present address: 4220 Franklin Street, Kensington, Md. 20795

${ }^{1}$ Figures in brackets indicate the literature references at the end of this paper. whose temperature was controlled by pumping liquid from a temperature bath through coils around the chamber, and whose humidity was maintained by exposing inside the box either $\mathrm{P}_{2} \mathrm{O}_{5}$ for $<1.5$ percent relative humidity (rh) or a saturated $\mathrm{Mg}\left(\mathrm{NO}_{3}\right)_{2}$ solution for about 52 percent relative humidity. The humidity in the chamber was measured with an electric hygrometer.

In the frequency range from $1 \mathrm{MHz}$ to $10 \mathrm{MHz}$ a $Q$-meter was used for dielectric constant and dissipation factor measurements. The cell used was a twoterminal micrometer-electrode cell mounted in a box whose temperature and humidity were controlled in a manner similar to that used for the three-terminal cell. A two-terminal Schering bridge was used to coordinate the $Q$-meter measurements with the more accurate three-terminal data.

\section{Specimens}

\subsection{Contact Electrodes}

Many of the measurements were made without contact electrodes using the air-gap technique [5] with $8.5 \mathrm{~cm}$ diam disks from $2 \mathrm{~mm}$ to $5 \mathrm{~mm}$ thick. Disks with $3.8 \mathrm{~cm}$ diam were prepared with contact electrodes so that specimens might be measured at higher frequency with the $Q$-meter and used to calibrate two-terminal equipment. Heavy gold electrodes, about $1500 \AA$ thick, were evaporated on the faces of these similar specimens to form the contact electrodes. Care was always taken to see that the resistance across the electrode surface was never more than a few tenths of an ohm. 


\subsection{Surfacing Specimens}

At the beginning of this study a modified Schiefer abrasion machine was used to surface the specimens [6]. Even though this method produced specimens with thicknesses uniform to within $6 \mu$, we later used a technique which produced more uniform thicknesses. The second method made use of a vacuum chuck and a fly cutter on a milling machine. The vacuum chuck consisted of a metal vacuum chamber with holes drilled in one side for holding the specimen in place and could be positioned on a milling machine for successive passes made with the cutter. The specimen was turned over or rotated with each pass until the faces became quite parallel. With careful preparation of the cutting tool and proper adjustment of the cutting rate, this technique could produce specimens with thicknesses uniform to within $3 \mu$ over an $8.5 \mathrm{~cm}$ diam.

\subsection{Measuring Thicknesses}

The specimen thicknesses were measured with an indicating micrometer having a reference point set by gage blocks. Measurements were made at points around concentric circles as determined by a pattern. These numbers were averaged to determine the measured thickness. Comparisons indicate agreement to 0.05 percent between the micrometer thickness and that determined with the two-fluid electrical technique [7].

\subsection{Storage}

Between measurements and for initial conditioning, specimens were stored in glass vessels with humidity controlled in the same manner as in the measuring chamber.

\subsection{General Properties}

The suppliers indicated the following general properties for the various materials. The polyethylene was the high molecular weight, low pressure type. It had a linear structure with no detectable branching and a crystallinity of from 90 to 95 percent. The T-16 polyester was a linear, thermoplastic, crystallizable polymer about 36 repeating units long. It had a crystal melting point of around $265^{\circ} \mathrm{C}$ and a glass transition at about $87{ }^{\circ} \mathrm{C}$. The polycarbonate material contained no plasticizers and had a molecular weight ranging around 30,000 to 35,000 . The polystyrene material was reported to be of high purity. PTFE and FEP specimens were from laboratory grade stock.

The polyethylene specimens and certain of the polystyrene specimens were compression molded in our laboratory. The polycarbonate specimens were impact molded, the T-16 specimens were injection molded, and the FEP and PTFE specimens were compression molded, all by the supplier.

\subsection{Density}

The density of most specimens was measured in order to characterize the materials better and to provide a rough measure of the uniformity of specimens from the same material. Two methods were used for determining density. In the first method the volume of the specimen was determined by liquid displacement. The second method was based on dimensional volume measurements. Since our specimens were very carefully machined disks, they were, in fact, good approximations of right circular cylinders. By measuring the diameter with a traveling microscope and using the thickness, we could calculate a dimensionally determined volume. The same mass data was used with each volume to calculate two different densities. Based on repeated measurements and calibration of the traveling microscope, we estimate the dimensional volume measurement to be accurate within about 0.1 percent; however, the liquid displacement densities were consistently larger than the dimensional densities by 0.1 percent to 0.5 percent, even though care was taken to reduce errors caused by insufficient surface wetting of the specimen and by surface tension acting on the suspension wire. Since the dimensional measurements also produced much more reasonable relationships between the dielectric constant and density, it was concluded that our liquid displacement measurements were less accurate, so all the density data presented were determined from mass and dimensional measurements.

\section{Measurement Procedure}

The following procedure was used to obtain the dielectric properties of individual specimens as functions of time after humidity change. Each specimen was stored in a chamber with the desired relative humidity until it reached equilibrium, i.e., until its dielectric properties no longer changed with time. A timed humidity run was then begun by transferring the specimen to another chamber at the new humidity. Periodic measurements were made with careful note being taken of the elapsed time since the humidity change. All timed humidity run data as well as frequency sweep data were taken at $23{ }^{\circ} \mathrm{C}$.

It was observed for some of the electrodeless specimens that slightly different values of dielectric constant and dissipation factor were obtained when the specimen was turned over. The amount of this effect varied from specimen to specimen, and for some disks only the dielectric constant differed significantly. Differences as large as 0.2 percent in the dielectric constant were observed. This behavior was caused by the specimens being slightly curved instead of flat although they were of uniform thickness. In some cases it was possible to partially flatten out the warped specimens, and this reduced the difference. Whenever possible, the same face was kept turned up throughout the timed humidity runs; however, for some of the older data, taken before the effect was discovered, this was not done.

\section{Results}

\subsection{Timed Humidity Runs}

Figures 1 through 7 show timed humidity runs measured at $1000 \mathrm{~Hz}$ for certain specimens of the various 
materials. For all of these figures, time from humidity change is plotted on the horizontal axis using a logarithmic scale, and those points marked with arrow heads on the left-hand margin of some of the plots indicate zero time starting values, which are measurements made at the storage humidity shortly before the beginning of the timed humidity run. Even though there are usually curves from only one or two specimens for a given material, the trends are generally representative for several of our specimens. All the dielectric properties given here were measured using the airgap technique except when contact electrodes are indicated.

Figure 1 shows a plot for a $\mathrm{T}-16$ specimen going from $<1.5$ percent $\mathrm{rh}$ to 52 percent $\mathrm{rh}$ after being exposed to the low humidity for 455 days. This material does not show long term stability as indicated by the negative slope of the curves after about 100 days. We suggest that this aging process may be due to very slow crystallization of this material. We offer this as a possible explanation, even though the specimens were kept well below the glass transition temperature, because the material was not completely amorphous and the trend is indeed in the direction of higher crystallinity. Other specimens of this material in both humidities also showed this downward trend with time.

Figure 2 is a plot for two contact electrode specimens of polystyrene going from 52 percent $\mathrm{rh}$ to $<1.5$ percent rh. The specimen for curve $\mathrm{A}$ had been in 52 percent rh for 1600 days, and the specimen for curve $\mathrm{B}$ had been in 52 percent rh for 74 days.

In figure 3 are curves for two specimens of polycarbonate. The specimen producing curve $\mathrm{A}$ was in 52 percent rh for 992 days before the humidity change and likewise the specimen for curve $\mathrm{B}$ was in $<1.5$ percent $\mathrm{rh}$ for 1096 days before the change. These curves show the reversibility of the process, but the long time data seem to indicate an aging process again. Figure 4 shows curves for a polycarbonate specimen differently prepared by the manufacturer; this specimen had been in 52 percent rh for 174 days. Aside from
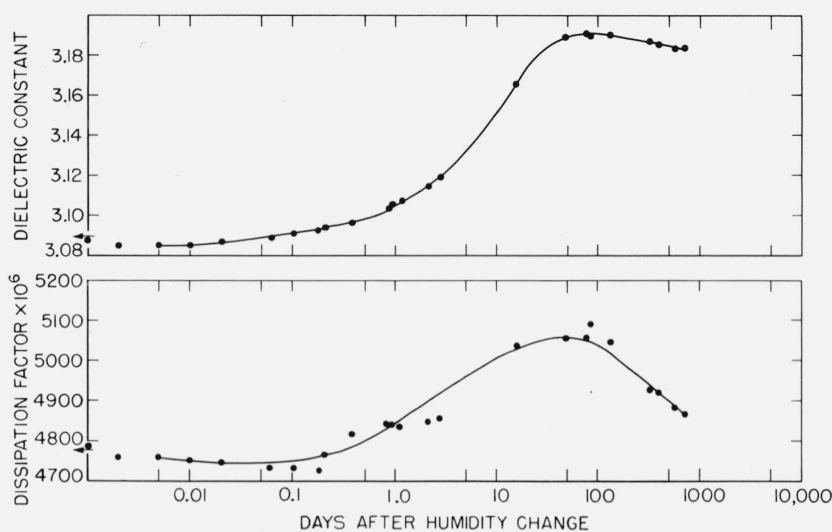

FigURE 1. Timed humidity run for a specimen of T-16 going from $<1.5$ percent rh to 52 percent $r h$.
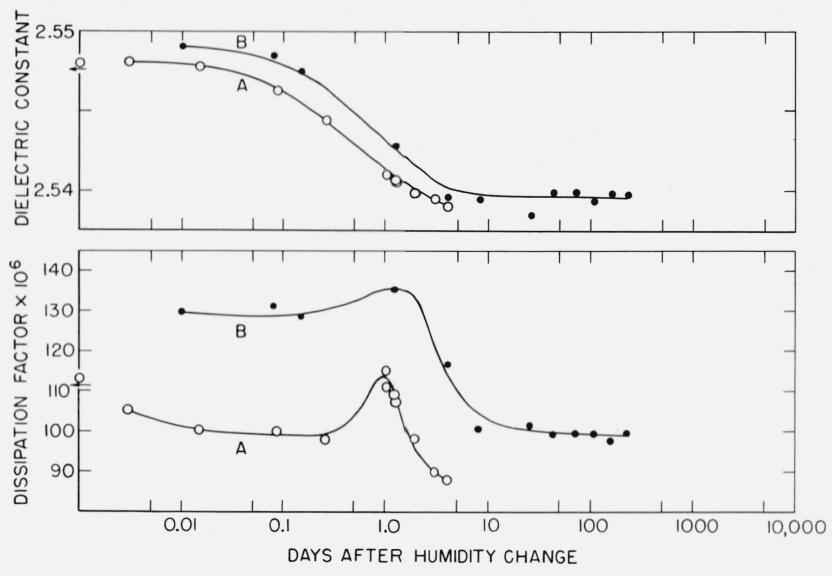

FigURE 2. Timed humidity runs for two contact electrode specimens of PS going from 52 percent rh to $<1.5$ percent rh.

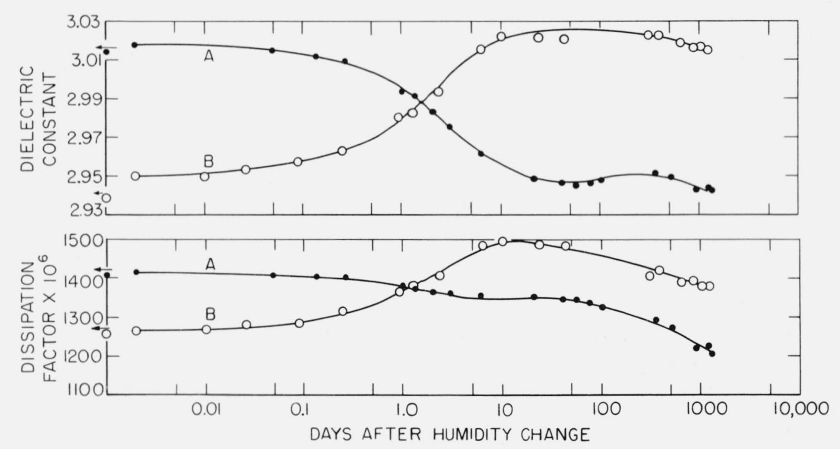

FiguRE 3. Timed humidity runs for two specimens of PC.

Specimen A going from 52 percent rh to $<1.5$ percent rh. and specimen B going from $<1.5$ percent rh to 52 percent rh.
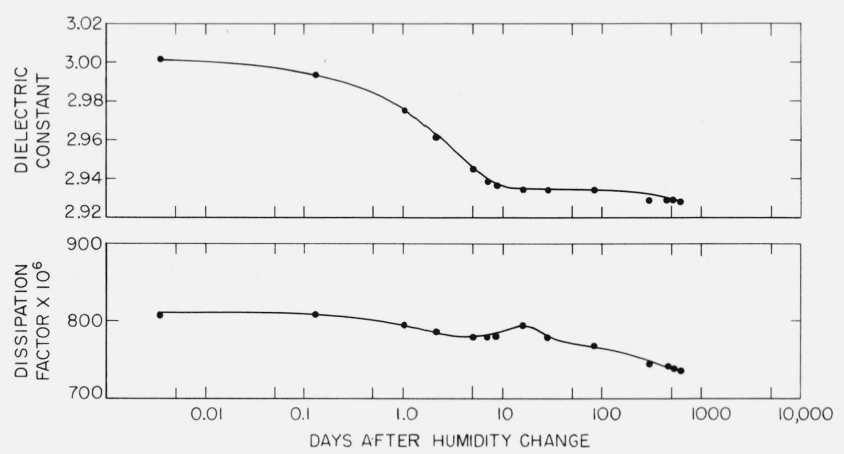

FIGURE 4. Timed humidity run for a specimen of differently prepared $P C$ going from 52 percent rh to $<1.5$ percent $\mathrm{rh}$

a lower dielectric constant and dissipation factor, the behavior indicated is about the same.

The data in figure 5 are for a specimen of FEP which was in $<1.5$ percent rh for 448 days before the change; these curves show a slight upward trend going from $<1.5$ percent rh to 52 percent $r$. However, within the 


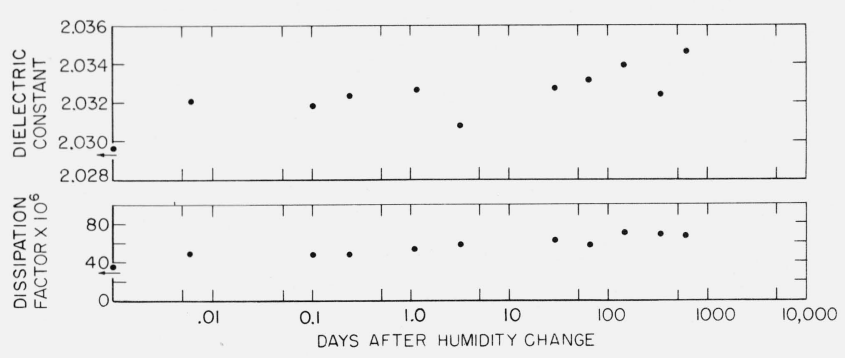

FIGURE 5. Timed humidity run for a specimen of FEP going from $<1.5$ percent rh to 52 percent $r$.
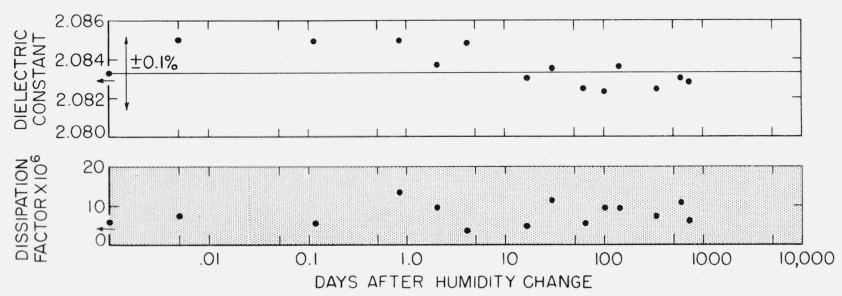

FIGURE 6. Timed humidity run for a specimen of PTFE going from $<1.5$ percent rh to 52 percent rh.

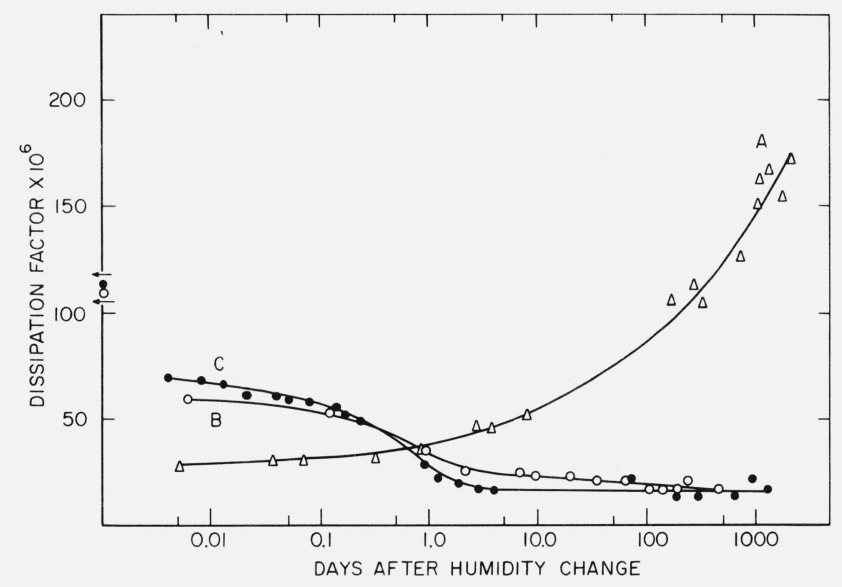

FIGURE 7. Timed humidity runs for three specimens of PE. Specimen A going from $<1.5$ percent rh to 52 percent $\mathrm{rh}$, and specimens $\mathrm{B}$ and $\mathrm{C}$ going from 52 percent $r$ to $<1.5$ percent $r$.

limit of our estimated accuracy, no change is indicated by the curves for the PTFE specimen in figure 6 . This specimen was in $<1.5$ percent $\mathrm{rh}$ for 453 days before the change to 52 percent $r$. In fact, no change was observed for any specimen of PTFE.

Figure 7 contains curves for specimens of polyethylene. Curve A shows the very slow rise in dissipation factor going from $<1.5$ percent rh to 52 percent rh for a contact electrode specimen which had been in $<1.5$ percent rh for 199 days. No change in dielectric constant has been observed for any polyethylene specimen. The specimen producing curve B was in 52 percent rh for 700 days before the change while the

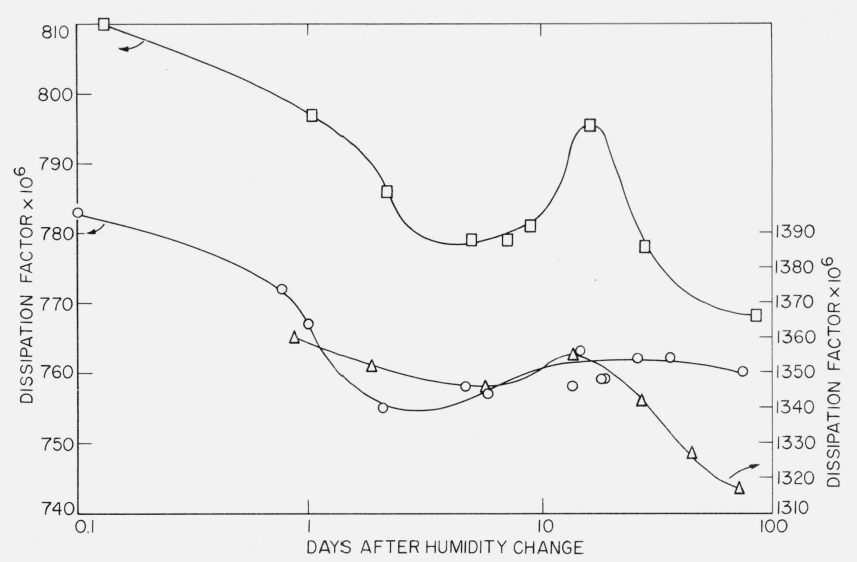

FIGURE 8. An expansion of timed humidity runs for three specimens of $P C$ going from 52 percent rh to $<1.5$ percent $r h$.

contact electrode specimen associated with the curve C was in 52 percent $\mathbf{r h}$ for 123 days. Taken together these data would seem to indicate that, even though water is sorbed into polyethylene slowly, some of the water is released very quickly.

In figure 2 there are peaks in the PS dissipation factor curves after one day. Figure 8 shows similar peaks for three specimens of $\mathrm{PC}$ on an expanded time scale, but for this material the peak is in the region of 10 to 30 days. This strange behavior was observed only on PS and PC specimens. Moreover, it has been observed for specimens measured with contact electrodes as well as with the air-gap method. No explanation has been found for this unusual data.

\subsection{Frequency Sweeps}

Figure 9 contains the dielectric constant and dissipation factor plotted against frequency for a contact electrode specimen of $\mathrm{PC}$; these data were measured at $<1.5$ percent $\mathrm{rh}$ equilibrium. Figure 10 likewise shows the dissipation factor and dielectric constant for contact electrode specimens of PS at both $<1.5$ percent rh and 52 percent rh equilibrium. Figure 11 contains similar plots for two $\mathrm{T}-16$ specimens.

From the other materials-PE, PTFE, and FEP - no specimens showed a significant change in dielectric constant over our frequency range. Dissipation factor data for FEP specimens at both the low and high humidity appear in curves $\mathrm{A}$ and $\mathrm{B}$ in figure 12 . The dissipation factors for $\mathrm{PE}$ specimens at $<1.5$ percent rh measured less than the limit of our accuracy so were not plotted, but 52 percent $\mathrm{rh}$ data appear as curve $\mathrm{C}$ in figure 12 .

Results differed slightly from specimen to specimen for most measurements; this was especially true at 52 percent $\mathrm{rh}$. We were ultimately concerned more with the careful recording of the behavior of a particular specimen or group of specimens than with the general material, so none of the data presented here should be taken to represent the whole material in a detailed way. 


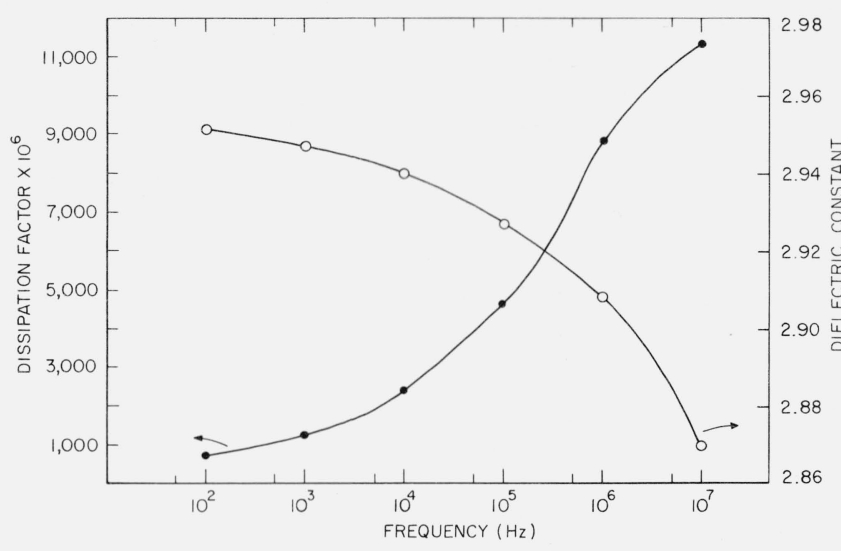

Figure 9. Dielectric constant and dissipation factor versus frequency for a contact electrode specimen of $P C$ at $<1.5$ percent $r h$ equilibrium.

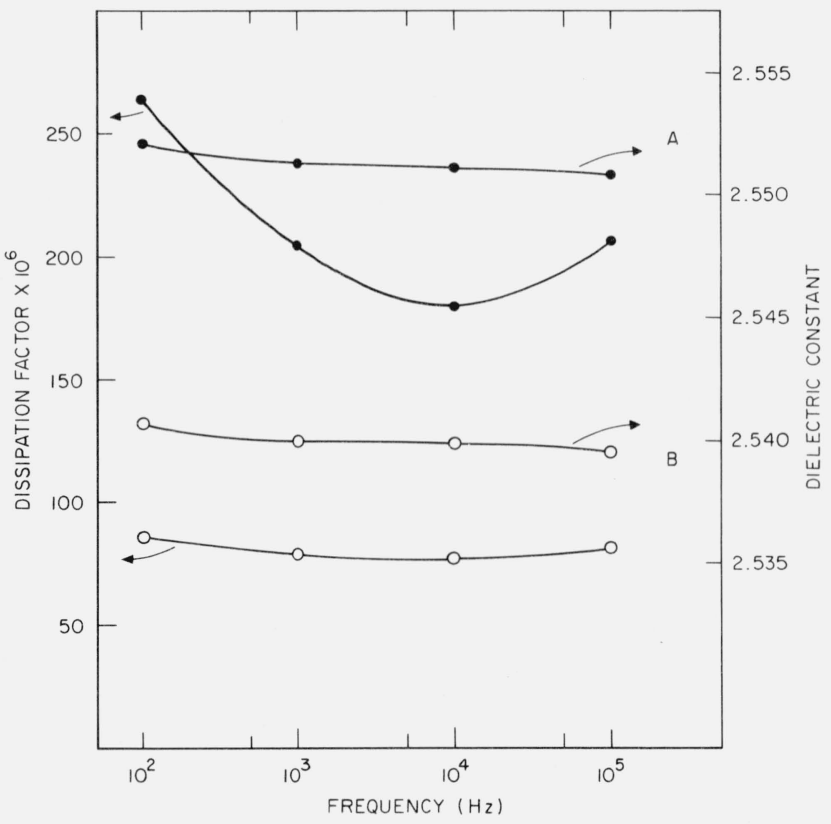

FigurE 10. Dielectric constant and dissipation factor versus frequency for two contact electrode specimens of PS.

Specimen $\mathrm{A}$ is in 52 percent rh equilibrium and specimen $\mathrm{B}$ is in $<1.5$ percent rh equilibrium.

\subsection{Density and Water Absorption}

A linear relationship between the dielectric constant and density is a good approximation over a restricted density range for polyethylene. The common form for this relation is the Clausius-Mossotti equation,

$$
\frac{\epsilon^{\prime}-1}{\epsilon^{\prime}+2}=K \rho,
$$

where $\rho$ is the density, $\epsilon^{\prime}$ is the dielectric constant, and $K$ is a constant for the material which depends on the molecular weight and the total polarizability per mole-

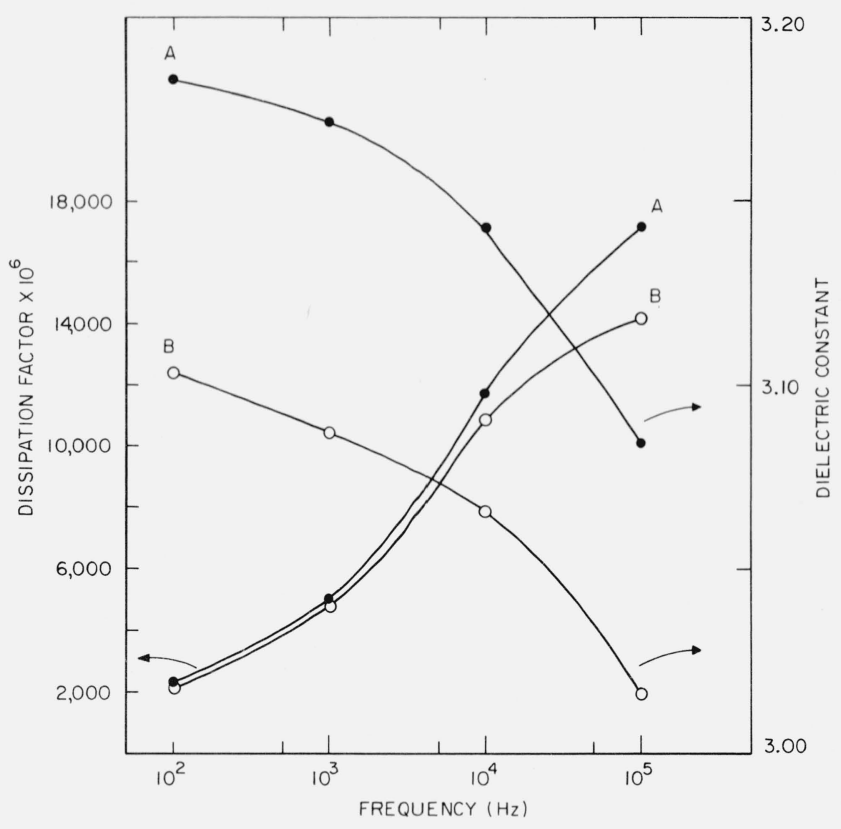

FigURE 11. Dielectric constant and dissipation factor versus frequency for two specimens of T-16.

Specimen $\mathrm{A}$ is in 52 percent $\mathrm{rh}$ equilibrium and specimen $\mathrm{B}$ is in $<1.5$ percent $\mathrm{rh}$ equilibrium.

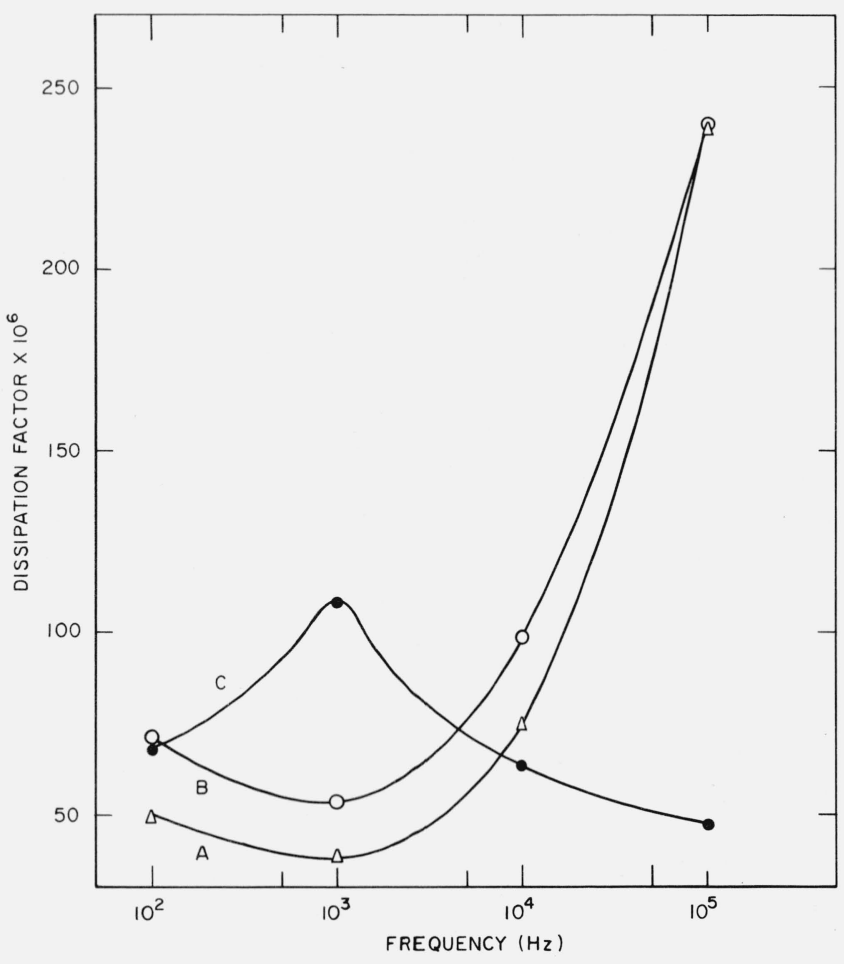

Figure 12. Dissipation factor versus frequency for specimens of FEP and PE.

Specimen A is FEP at $<1.5$ percent rh equilibrium; specimen B is FEP at 52 percent $\mathrm{rh}$ quilibrium; and specimen $\mathrm{C}$ is $\mathrm{PE}$ at 52 percent rh equilibrium. 


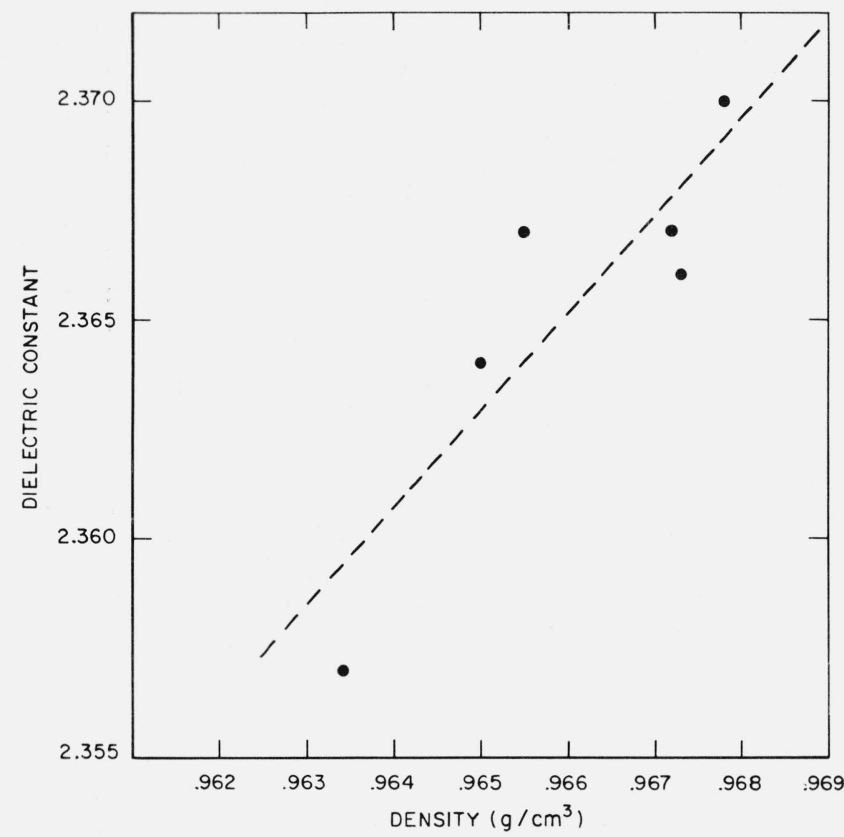

FIGURE 13. Dielectric constant versus density for specimens of polyethylene.

cule. The dielectric constant of six PE specimens is plotted versus density in figure 13. A straight line was fitted to the data by a method, useful when the errors in the variables are unknown, as given by Bartlett [8], and this line is also shown. These differences in density were probably caused by the slightly different thermal and mechanical treatment received during molding and machining.

Some effort was made to determine the amount of water absorbed by certain specimens by taking the difference between the equilibrium weight at $<1.5$ percent $\mathrm{rh}$ and weight at room humidity which was generally 20 percent rh to 40 percent $\mathrm{rh}$ and never above 50 percent $\mathrm{rh}$. A difference in weight of 0.03 percent was obtained from the average change of two PS specimens. This roughly agrees with the value observed by von Hippel and Wesson [9] of 0.048 percent for 60 percent rh at $25^{\circ} \mathrm{C}$. Likewise, for PC we observed a 0.13 percent change in weight which compares with the 0.15 percent observed by Thompson and Goldblum [10] for 50 percent rh. These can not be exact comparisons since the materials were, at best, only similar in composition, but they do show order of magnitude agreement. We were unable to detect a difference in weight for FEP, PTFE or PE even though the dissipation factor of PE showed a quite definite change going to 52 percent. The amount of water absorbed by $\mathrm{PE}$ has been shown to be quite small (on the order of 0.03 or $\left.0.06 \mathrm{mg} / \mathrm{cm}^{3}\right)[11,12]$, and beyond the sensitivity of our weighing system.

\section{Estimated Error Limits}

From the use of this low-voltage conjugate Schering bridge over a long period of time, it is estimated that repeated measurements of capacitance over the frequency range $100 \mathrm{~Hz}$ to $100 \mathrm{kHz}$ could be expected to agree to within $\pm 0.001 \mathrm{pF}$ for measured capacitances above $10 \mathrm{pF}$ and $0.0001 \mathrm{pF}$ for $10 \mathrm{pF}$ and below. Based on this estimate and comparisons with the twofluid technique as well as repeated determinations, we estimate our dielectric constant measurements using this bridge and the air-gap technique to be accurate within \pm 0.1 percent.

Previous papers by Scott and Harris [2, 13] discuss some of the important problems involved in the measurement of small dissipation factors. Significant errors can arise if both the high and low sides of the circuit have some finite common impedance to ground. In general, this is the case with a three-terminal cell or capacitor. It is possible, in principle, to completely analyze the circuits involved for a given cell and bridge to allow the most accurate dissipation factor determination; however, that study has not yet been completed for our equipment. Heating by the measuring field can also be a problem with higher loss specimens, since the properties may change rapidly with temperature and frequency, so we have included large percentage limits with the estimated accuracies for the dissipation factor.

From the use of this Schering bridge over a long period of time, in the same manner as capacitance, it is estimated that repeated measurements of the dissipation factor of a stable specimen could be expected to agree within $2 \times 10^{-6}$, and based on this and comparisons with carefully constructed low loss capacitors, we estimate the absolute and relative dissipation factor measurements using this bridge to be accurate within the greater of the two limits given in their respective columns in table 1.

The dissipation factor measurements made using the $Q$-meter with an extra-high- $Q$ coil at $1 \mathrm{MHz}$ are estimated to be accurate within \pm 0.0002 . At 10 $\mathrm{MHz}$, this accuracy was reduced somewhat due to the uncertainty of corrections for lead inductance. The dielectric constant measurements made with this $Q$-meter are believed to be accurate within \pm 0.2 percent. These estimates were derived from measurements made on specimens whose properties at $1 \mathrm{MHz}$ and $10 \mathrm{MHz}$ were believed to be essentially the same as at lower frequencies, where they could be determined more accurately.

TABLE 1. Estimated error limits for absolute and relative dissipation factor measurements made with the low-voltage conjugate Schering bridge are given by greater of the two values

\begin{tabular}{c|c|c}
\hline \hline Frequency & Absolute error limits & Relative error limits \\
\hline & & \\
$10^{2}$ & $\pm 30 \times 10^{-6}$ or $\pm 2 \%$ & $\pm 20 \times 10^{-6}$ or $\pm 2 \%$ \\
$10^{3}$ & $\pm 20 \times 10^{-6}$ or $\pm 1 \%$ & $\pm 10 \times 10^{-6}$ or $\pm 1 \%$ \\
$10^{4}$ & $\pm 20 \times 10^{-6}$ or $\pm 1 \%$ & $\pm 10 \times 10^{-6}$ or $\pm 1 \%$ \\
$10^{5}$ & $\pm 40 \times 10^{-6}$ or $\pm 3 \%$ & $\pm 30 \times 10^{-6}$ or $\pm 3 \%$ \\
\hline
\end{tabular}

\section{Discussion}

The PC and T-16 timed humidity runs show large rapid changes as well as the long term drift. If these 
materials were to be used for making dielectric reference specimens, it would be necessary to carefully control the humidity, and obviously their usefulness would be limited at best. The PC data does give a clear indication of the reversibility of this process for the same or a similar specimen, and therefore, if a copy of the timed humidity run were sent along with a specimen, a somewhat more accurate characterization could be obtained under a large variety of conditions.

For the PS specimens, the change was not nearly so great; however, it would still be necessary to take the humidity into account to obtain an accuracy better than about 1 percent for dielectric constant and about $1 \times 10^{-4}$ for dissipation factor.

The PE data show a very rapid initial change in the dissipation factor when the relative humidity is changed from 52 percent $\mathrm{rh}$ to $<1.5$ percent $\mathrm{rh}$, but quite a slow drift upward on the return to 52 percent $r$. This behavior coupled with the lack of a change in the dielectric constant means that it would be possible to predict a specimen's properties quite well if it were stored in low humidity before and after a measurement even if the measurement were made at a higher humidity.

PTFE, and FEP to possibly a slightly less degree, are materials well suited for dielectric reference specimen preparation. Although the FEP dielectric constant and dissipation factor data seem to show an upward trend going from $<1.5$ percent rh to 52 percent rh, lines fitted by the least squares method versus the logarithm of time after humidity change do not have slopes statistically different from zero. For PTFE, no change in dielectric constant or dissipation factor is indicated within our error limits for the $100 \mathrm{~Hz}$ to $10 \mathrm{MHz}$ frequency range or for a change in humidity.

The authors thank the following manufacturers for their assistance by supplying the materials used in this study. Allied Chemical Corp., Dow Chemical Co., E. I. du Pont de Nemours and Co., General Electric
Co., Phillips Chemical Co., and Tennessee Eastman Co.

We also thank M. G. Broadhurst and W. P. Harris for their very valuable assistance and advice.

\section{References}

[1] A. H. Scott and W. P. Harris, Residual losses in a guard-ring micrometer-electrode holder for solid-disk dielectric specimens, J. Res. NBS 65C (Phys. and Chem.) No. 2, 101 (1961).

[2] A. H. Scott and W. P. Harris, Long-time effects of humidity changes on the dielectric properties of certain polymers, 1962 Annual Report, Conference on Electrical Insulation, Nat. Acad. Sci. - Nat. Research Council, Publ. 1080, p. 41.

[3] J. I. Lauritzen, Jr., The effective area of a guarded electrode, 1963 Annual Report, Conference on Electrical Insulation, Nat. Acad. Sci.-Nat. Research Council, Publ. 1141, p. 67.

[4] W. P. Harris, Precise determination of the area of guarded electrodes for accurate dielectric measurements on solid disk specimens, 1963 Annual Report, Conference on Electrical Insulation, Nat. Acad. Sci.-Nat. Research Council, Publ. 1141, p. 71.

[5] A. H. Scott, Techniques for using the air-gap method for the precise determination of the dielectric constant and loss angle of solid disk specimens, 1963 Annual Report, Conference on Electrical Insulation, Nat. Acad. Sci.-Nat. Research Council, Publ. 1141, p. 74.

[6] H. F. Schiefer, L. E. Crean, and J. F. Krasny, J. Res. NBS 42, 481 (1949), RP1988.

[7] W. P. Harris and A. H. Scott, Precise measurement of dielectric constant by the two-fluid technique, 1962 Annual Report, Conference on Electrical Insulation, Nat. Acad. Sci.-Nat. Research Council, Publ. 1080, p.51.

[8] M. S. Bartlett, Fitting a straight line when both variables are subject to error, Biometrics 5 (Sept. 1949), No. 3, p. 207.

[9] A. von Hippel and L. G. Wesson, Polystyrene plastics as high frequency dielectrics, Industrial and Engineering Chemistry 38, No. 11, p. 1121 (1946).

[10] R. J. Thompson and K. R. Goldblum, Polycarbonate resin, Modern Plastics 35 (April 1958), p. 131.

[11] C. H. Klute, Diffusion of small molecules in semicrystalline polymers: water in polyethylene, J. of Applied Polymer Science 1, No. 3, p. 340 (1959).

[12] D. W. McCall, J. F. Ambrose, and V. L. Lanza, J. of Polymer Science 26, 165 (1957).

[13] W. P. Harris, Apparent negative impedances and their effect on three-terminal dielectric loss measurements, 1965 Annual Report, Conference on Electrical Insulation, Nat. Acad. Sci.-Nat. Research Council, Publ. 1356, p. 83.

(Paper 71C2-251) 